\title{
Changing Territories of Health Care Professionals in Primary Care
}

\section{Kieke GH Okma*}

\author{
Visiting Professor, Catholic University Leuven, Belgium
}

*Corresponding author: Kieke GH Okma, Visiting Professor, Catholic University Leuven, Belgium, E-mail: kiekeokma781@ gmail.com

\begin{abstract}
This contribution explores the changing positions of four major groups of health professionals in primary care in North America and Western Europe: general internists, family physicians, nurse practitioners and physician assistants. The mix of professionals varies greatly across countries in Europe and North America, illustrating that there is no single answer to the question: "What is the 'best' mix of health professionals?" The central questions of this study are: What explains the changing positions of the physicians, nurse practitioners and physician assistants in those regions; what is the future outlook of those groups? Nurses are the largest group of highest qualified health professionals. Over three million registered nurses work in the U.S. Some of those, in particular nurse practitioners (NPs) have, similar to physician assistants (PAs), gained independent status in seeing patients, prescribing medicine and referring to other professionals. But as their incomes continue to rise, the financial advantage of hiring NPs or PAs over physicians becomes less obvious, and they face competing claims of other health professionals in the field.
\end{abstract}

\section{Keywords}

Professionalization, Overlapping professional domains, Health care professionals, Primary care workforce, General internal medicine, Family practitioners, Nurse practitioners, Physician assistants

\section{Introduction}

This contribution explores the changing positions and future outlook of four groups of health professionals in primary care in North America and Western Europe: general internists (GIMs), family physicians (FPs), nurse practitioners (NPs) and physician assistants (PAs) ${ }^{a, b}$. This contribution focuses on the GIMs, PFs, NPs and PAs. There are other groups that consider themselves primary care providers. In the U.S., for example, those include OB/GYN, pediatrics, geriatrics, as well as some other non-physician clinicians. The four groups selected here are the largest and most 'visible' in the debate over primary care in the North America.

This study is, in a wider sense, a comparative study of professionalism. The issues discussed are not unique to primary care or unique to one country only. In law and architecture, for example, experienced assistants routinely take on work of lawyers or architects [3,4]. Similarly, dental hygienists have taken over many routine activities of dentists and often practice independently [5].

The professional fields include several functions. For example, GIM and FP physicians generally assess and diagnose patients, prescribe drugs, commission laboratory testing; refer to other specialists, discuss treatment options with patients and in some cases, perform minor surgery. Each function consists of several activities. Assessment and diagnosis, for example, generally include taking of patient and family history of illness, measuring of basic vitals, basic in-office testing; framing tentative diagnosis and discussing options for further action with patients and their families.

Many activities that originally were part of the exclusive domain of physicians have shifted, in varying degrees across countries, to NPs, PAs and other health care work-

\footnotetext{
aThis contribution draws substantially on an earlier study of the changing field of primary care [1].

'The term "primary care" applies to a strikingly divergent range of health care services across countries. In the international policy debate, there is much support for "primary-care led health reform", but little clarification what that means in any operational way [2]. Without commonly accepted operational definitions, it is hard if not impossible to assess claims about the 'best' primary-care model, the merits of 'primary-care led reforms,' or about the 'proper' roles of professionals in the field.
}

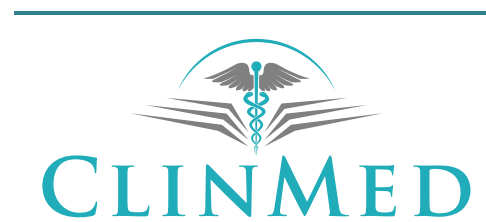

Citation: Okma KGH (2017) Changing Territories of Health Care Professionals in Primary Care. Int Arch Nurs Health Care 3:067. doi.org/10.23937/2469-5823/1510067

Received: August 27, 2016: Accepted: April 14, 2017: Published: April 17, 2017

Copyright: (C) 2017 Okma KGH. This is an open-access article distributed under the terms of the Creative Commons Attribution License, which permits unrestricted use, distribution, and reproduction I NTER NAT IONAL LI B RARY in any medium, provided the original author and source are credited. 
ers. It is hard to assess that shift in a quantitative way. While there is a large body of (largely descriptive and often aspirational) literature about the four main groups discussed in this article, there are no studies that present a quantitative picture of shifts in professional activities from one group to another. This analysis of changing positions of the four groups is therefore somewhat exploratory, mostly based on aggregate data and reports of governments and professional associations.

Most emphasis will be on The United States, as there are many more NPs and PAs working in this country than elsewhere and most of the literature on those professional groups stems from this country. While many European nations have discussed the need to develop education for NPs and PAs for over two decades, they did not follow up with substantial action. The numbers of NPs and PAs remained very low indeed.

\section{The Changing Positions of General Internal Med- icine and Family Practitioners}

In the United States, the total workforce in health care and social assistance was over 20 million persons in 2013 , about $15 \%$ of the total labor force, including three million nurses and almost one million physicians. In the past, projections of substantial future shortages of physicians or nurses regularly prompted expansion of medical and nursing schools [6,7]. Several medical schools and nursing schools increased their capacity in the early 2000s. Similar debates and action took place in other countries. Critical commentators, however, foresaw another cycle of oversupply [8,9]. Given the large variation in the projections, they advocated reassessment of the existing skill mix before expanding educational capacity.

Between 1975 and 2012, the number of American physicians more than doubled, and medical specialties grew from 20 to 219. GIM and FPs saw their numbers increase even faster (Table 1). At the same time, there was a phenomenal growth in numbers of licensed non-physician clinicians (NPCs) ${ }^{c}$, including NPs, PAs, midwives, chiropractors, acupuncturists, naturopaths, optometrists, podiatrists and nurse anesthetists [11,12]. The lack of coordination between regulatory and licensing bodies also contributed to the growing overlap in professional activities.

Internal medicine emerged as a specialty in the United States in the 1880s, based on the German model of physicians with advanced training in clinical medicine, pathology and research [13]. In contrast to British GIMs who almost exclusively served as hospital-based consultants to general practitioners, the role of American internists was never clearly defined. In the first half of the $20^{\text {th }}$ century, American GIMs sought to carve out a unique role as generalists in primary care, serving as consultants for complex medical cases and bringing lab-

'The NP Association does not like the term 'non-physician practicing clinician' (NPC). The term is "vague," "not descriptive of NPs," it argues, "lacking any specificity by aggregately including all healthcare providers who are not licensed as an MD or DO" [10]. The AANP prefers the terms "independently licensed providers," "primary care providers," "healthcare professionals" and "clinicians" when referring to NPs. This contribution uses the term NPC. However, as it is commonly used in the literature and the proposed alternatives do not solve the definitional problems.

Table 1: Physicians, RNs, NPs and PAs in the United States, 1975-2016 (numbers of professionals).

\begin{tabular}{|c|c|c|c|c|c|c|c|}
\hline & Physicians & $\begin{array}{l}\text { Active phy- } \\
\text { sicians }\end{array}$ & $\begin{array}{l}\text { General internal } \\
\text { medicine }\end{array}$ & $\begin{array}{l}\text { Family practi- } \\
\text { tioners }\end{array}$ & $\begin{array}{l}\text { Registered } \\
\text { nurses }\end{array}$ & $\begin{array}{l}\text { Nurse practi- } \\
\text { tioners }\end{array}$ & $\begin{array}{l}\text { Physicians } \\
\text { assistants }\end{array}$ \\
\hline 1975 & 393,742 & 366,425 & 47,761 & 12,183 & - & - & - \\
\hline 1980 & 467,679 & 435,545 & 58,462 & 27,530 & - & - & - \\
\hline 1985 & 552,716 & 511,090 & 70,691 & 40,021 & - & - & - \\
\hline 1990 & 615,421 & 559,988 & 76,295 & 47,639 & - & 24,000 & 20,448 \\
\hline 1995 & 720,325 & 646,022 & 88,240 & 59,109 & - & 50,000 & 26,895 \\
\hline 2000 & 813,770 & 737,504 & 101,353 & 71,102 & - & 68,000 & 39,420 \\
\hline 2005 & 902,053 & 801,742 & 112,934 & 80,809 & - & 109,000 & 58,665 \\
\hline 2008 & 954,224 & 834,546 & 115,314 & 84,197 & - & 125,000 & 68,124 \\
\hline 2009 & - & - & - & - & - & - & 72,433 \\
\hline $2010 / 2011$ & 987,000 & 834,769 (a) & $164,187(a)$ & $116,933(a)$ & $2,737,400$ & $180,233(a)$ & 83,540 \\
\hline 2016 & $1,045,910$ & 854,698 & 178,497 & 127,662 & $3,129,452$ & 175,021 & 91,994 (5) \\
\hline \multicolumn{8}{|c|}{$\begin{array}{l}\text { Average annu- } \\
\text { al growth rate }\end{array}$} \\
\hline $1975-1990$ & $3.8 \%$ & $10 \%$ & $10.5 \%$ & $26 \%$ & - & - & - \\
\hline 1990-2016 & $5.6 \%$ & $4.6 \%$ & $9.0 \%$ & $10.2 \%$ & - & $28.0 \%$ & $17.7 \%$ \\
\hline
\end{tabular}

Sources [11,65,71-74], (1) 1989, (2) 1991, (3) 1996, (4) 1999, (a) kff.org, there are some inconsistencies due to the different statistical sources but the numbers show overall trends. 
oratory science to the wards.

Family medicine became a separate specialty in the late 1960s. American family practitioners (FPs) typically worked solo or in small group practices, in particular in small towns and rural areas. Until the 1980s, many American families considered FPs as their main primary care providers. The idea of generalists as gatekeepers to the medical system gained ground in the 1960s. Governments and insurers expected FPs and GIMs to act as cost-saving gatekeepers to hospital and specialist care, managing general medical problems and providing primary and preventive care [14]. With proper financial incentives, insurers and policy-makers believed, generalists would prevent hospitalization and save costs [3]. California's Kaiser Permanente and other HMOs increased GIM payments. Medical schools, with substantial financial support from federal government, expanded GIM training [13]. GIMs became independent practitioners with hospital privileges that allowed them to see their patients in the hospital. Meanwhile, by the mid- $20^{\text {th }}$ century, FP training had effectively eliminated the education gap between GIMs and FPs, and their positions had become very similar.

Disappointed with the results of gate keeping, however, HMOs adjusted payments for GIMs and FPs downwards in the late1980s and 1990s. The rise of new sub- specialties and new professionals, as noted above, created a crowded domain with growing overlap in functions and activities. It became harder to define (and defend) professional territories. Geriatrics, sports medicine, hospitalists and adolescent medicine, for example, carved out their niches from the traditional field of internal medicine. Hospitals employed hospitalists to replace the in-house coordinating role of GIMs and FPs [15]. At first, GIMs and FPs welcomed this as they could focus on treating their patients in the office, realizing it had become less economical to interrupt their practice to visit one or two patients in the hospital each day. But their scope for future expansion narrowed as other specialties took over responsibilities for specific patient groups (e.g., elderly, children, adolescents), and new NPC groups made inroads in primary care. "Primary Care in Crisis", two commentators concluded [16].

By the mid-1990s, American FP and GIM leaders claimed that their fields had become less attractive to medical students facing high amounts of debt but expecting lower future incomes. GIM residency posts remained vacant, and hospitals increasingly contracted physicians trained abroad. Solo FP practices declined rapidly since the 1990s, particularly in major cities with large immigrant populations. Activities of traditional family practice shifted

Table 2: Incomes of American GIMs, FPs, NPs and PAs, 1989-2016 (current US dollars).

\begin{tabular}{|c|c|c|c|c|}
\hline & General internal medicine & Family practitioners & Nurse practitioners & Physician assistants \\
\hline 1989 & 146,000 & 95,000 & - & - \\
\hline 1991 & 125,000 & 98,000 & - & - \\
\hline 1992 & 123,400 & 115,400 & 60,800 & 60,800 \\
\hline 1993 & 150,000 & 110,000 & - & - \\
\hline 1994 & - & - & - & - \\
\hline 1995 & - & 124,000 & - & - \\
\hline 1996 & - & - & - & - \\
\hline 1997 & - & - & - & 44,980 \\
\hline 1998 & - & - & - & 46,760 \\
\hline 1999 & 123,280 & - & - & 50,650 \\
\hline 2000 & 123,180 & - & - & 60,680 \\
\hline 2001 & 126,930 & - & - & 62,410 \\
\hline 2002 & 158,350 & - & - & 63,490 \\
\hline 2003 & 160,130 & - & - & 64,790 \\
\hline 2004 & 158,200 & 146,000 & - & 68,780 \\
\hline 2005 & 156,550 & - & - & 71,070 \\
\hline 2006 & 160,860 & 149,850 & - & 74,270 \\
\hline 2007 & 167,270 & - & - & 77,800 \\
\hline 2008 & 176,740 & 172,000 & 90,440 & 81,610 \\
\hline 2010-2011 & & - & - & 89,470 \\
\hline 2012 & & 189,000 & 90,580 & 94,870 \\
\hline 2016 & 201,920 & 189,000 & 99,000 & 99,000 \\
\hline
\end{tabular}

Sources $[24,59,62,67,75-78]$. There are some inconsistencies due to the variety of sources, but the data give an impression of the order of income growth rates. 
to other settings and to other health professionals.

Despite claims of decline, however, the numbers of GIMs and FPs per 100,000 residents grew faster than other physicians between 1975 and 2016 (Table 1). The numbers of NPs and PAs grew still much faster in the last two decades, suggesting a considerable shift of activity from physicians to NPCs. The total number of GIMs, FPs, NPs and PAs increased from 60,000 in 1975 (when there were no NPs or PAs registered) to 573,000 in 2011, a stunning almost tenfold growth of those four groups (America's population grew from 215 to 330 millions a 50 percent increase in that period).

The income gap between GIMs and FPs all but disappeared over time (Table 2). GIM incomes averaged about 223,000 dollars, those of FPs 227,000 dollars in 2015-not at the top of the totem pole, but higher than several other medical specialties [17]. Both NPs and PAs did well in pushing up their incomes. By 2016, the mean incomes of NPs and PAs were almost identical, both about 99,000 dollars [18]. While GIMs and FPs earned about three times as much as NPs and PAs in the mid1990s that difference had decreased to $50 \%$ by 2008 and even less by 2016. It is important to note that average income amounts hide large difference across practice settings and across regions or institutions.

GIM and FP publications expressed growing frustration about the erosion of their central role in primary care. The 2006 GIM ‘Blue Ribbon Committee' reiterated earlier complaints about their eroding position $[19,20]$. The Committee advocated a 'paradigm shift' to re-establish GIM as the 'core profession' in primary care, arguing that GIMs are well-placed to co-ordinate patient care and act as leaders of professional teams that include nurses, pharmacists, social workers and others. The Committee's report also advocated changes in medical education and loan forgiveness for medical students willing to specialize in this area. And finally, it revealed expansionary ambitions in managing information technology (IT). The electronic medical record (ERM) is 'high on the agenda,' though the Committee did not make quite clear what this meant ${ }^{d}$.

In terms strikingly similar to the GIM Committee, FP position papers claimed that current arrangements ignore their crucial role as 'core primary care professionals,' underutilizing their knowledge and experience [14]. Their incomes were stagnating in the early 2000s according to the Annals of Family Medicine, morale was low, and students showed less and less interest in becoming FPs [14]. The Annals advocated a 'holistic approach,' a 'new model of practice' that entails improved education, higher pay and expanded managerial responsibilities for FPs. Neither the GIM reports, however, nor the position papers of the FP referred to oth-

${ }^{\mathrm{d}} \mathrm{GIMs}$ are not the only group seeking more control over electronic medical records. There are competing claims of other groups about the 'ownership' of medical data and rules for access to medical records. er professionals in the field (especially NPs and PAs), apart from claiming a leadership role over 'teams'. A few years later, the American College of Physicians (ACP) presented a report [21], that somewhat hesitantly recognized the reality of increasing numbers of NPs in primary care, but advocated more research of models of practice and education before allowing full independence to NPs. It emphasized the difference between physicians and NPs in education and qualifications, but also acknowledged that in practice both groups' work had started to overlap.

Meanwhile, a Working Group of the European Federation of Internal Medicine (EFIM) presented its report in 2005 [22]. The group-in very similar terms as the reports of the American GIM-expressed, great concerns over the future of GIM in Europe. It defined internal medicine as "The modern, clinical, and scientific medical discipline that is responsible for the care of adult patients with one or more complex, acute or chronic illnesses. GIM is the cornerstone of an integrated health care delivery system that is needed today". At the same time, European policy-makers and health insurers started to look at the North American experience to explore ways to employ non-physician groups to take over activities as independent practitioners (for example, in Scotland) [23].

\section{Nurses}

Registered nurses (RNs) are the largest groups of higher educated health professionals in most industrialized nations. There are differences in how countries count their nursing workforce; some only include nurses that actually provide direct patient care, others include nurse managers and administrators as well. About half of the OECD countries consider midwives as specialized nurses. On average across OECD countries, there were 9.1 nurses per 1,000 populations in 2013, up from 8.4 in 2009 , with large variety across nations [24]. The ratios were generally higher in Switzerland 17.4 and Northern Europe than elsewhere: Denmark 16.3, Germany 13.8, The Netherlands 12.1, France 9.4, Italy and Portugal 6.1 and Spain 5.1 versus U.S. 11.1 and Canada 9.5. Those differences also resulted in strikingly different nurse: physician ratios: Finland 4.7, Japan 4.6, Denmark, 4.5, Switzerland 4.3, Norway 3.9, Netherlands 3.7, UK 3.0, and France 2.8 versus Canada 4.2 and the U.S. 4.1 (ibid.).

RNs work in a wide variety of inpatient and ambulatory care settings. Like physicians, nurses gained control over education, licensure and professional activities. By the end of the $20^{\text {th }}$ century, college level education had largely replaced the traditional in-house training of nurses across the OECD $[25,26]$. There were substantial differences in training, scope of practice and income level of nurses. The income differences however, were smaller than those for medical professionals. American nurses earned the highest net incomes, with low mandatory deductions and low average working hours, but they often have to purchase their own health insurance. 
Table 3: Incomes of registered nurses in selected OECD countries: net incomes, deductions, weekly hours and gross annual incomes, 2010 or latest available year (incomes in US ppp dollars).

\begin{tabular}{|l|l|l|l|l|}
\hline Country & $\begin{array}{l}\text { Net monthly income } \\
\text { (ppp dollars) }\end{array}$ & Compulsory deductions & Weekly hours & $\begin{array}{l}\text { Gross annual income } \\
\text { (ppp dollars) }\end{array}$ \\
\hline Australia & 2,703 & $21 \%$ & 38 & 41,058 \\
\hline Austria & 2,101 & $33 \%$ & 40 & 37,629 \\
\hline Canada & 2,217 & $30 \%$ & 31.7 & 38,057 \\
\hline Finland & 1,867 & $30 \%$ & 38.2 & 32,005 \\
\hline France (i) & 2,379 & $0 \%$ & 35 & 28,548 \\
\hline Germany & 2,078 & $27 \%$ & 39 & 34,158 \\
\hline Italy & 1,509 & $28 \%$ & 36 & 25,150 \\
\hline Japan & 1,820 & $16 \%$ & - & 26,000 \\
\hline Norway & 2,229 & $31 \%$ & 37.5 & 38,765 \\
\hline UK & 2,397 & $27 \%$ & 35.7 & 39,402 \\
\hline US & 3,168 & $22 \%$ & 33 & 48,738 \\
\hline
\end{tabular}

Source: [79] Deductions include income tax, social security, compulsory health insurance etc, (i) working hours in France are formally 35 hours since 2005 .

Even with support by their employer, premiums can be substantial. In the other countries, health premiums are usually included in the mandatory deductions. In France, employers pay all of those. Therefore, the differences between gross incomes are smaller than net incomes (Table 3).

Across countries, the nursing field expanded over time as nurses-in particular the nurse practitioners (see below)-took over activities from physicians; it contracted as managers and policy-makers increasingly sought to employ auxiliary nurses (LPNs and unlicensed assistants) for routine activities. Those workers had become the main providers of direct patient care in general hospitals, nursing homes and home care by the early $21^{\text {st }}$ century [27]. In some cases, activities shifted (back) from nurses to physicians. Anesthesiologists took over from specialized nurses in the decades after the Second World War, for example, and gynecologists expanded childbirth care at the cost of midwives. The nature of nursing changed as well. RNs increasingly spend more time in meetings, administrative work and coordinating care of others than in direct patient care [28]. The rise of new professional associations (of both nurse specialties and breakaway fractions like the new nurses association in California) caused similar to medicine-fragmentation of the nursing territory.

Nurses generally work in a "culture of uncertainty," and there is little agreement over their 'proper' role [29]. Nurses seem to be in search of an underlying theory of nursing or a specific "nursing paradigm" more than any other group of health professionals [30]. The debate about the very definition of nursing also raises the question how (if at all) nursing basically differs from medicine [31]. Nurses often feel that other actors ignore their potential for a much larger role. They may have considerable responsibilities but-with the notable exception of NPs, see below-limited authority. Reflecting religious and military origins, many hospitals are still hierarchical institutions, where nurses feel subordinated to administrators and (male) specialists [32].

American nurse leaders have proposed a variety of nursing models to redefine the professional field, rang- ing from the "team model" [33], or the "clinical nurse leader" [34], to the "advance practice nursing model" [35]. Some questioned the wisdom of shedding menial and routine activities to lower skilled workers [36]. As a response to the narrowing field, the "primary care nursing" model assumes RN responsibility for the entire range of nursing activities-as well as a fair part of medical care [35]. Despite efforts to define nursing as a specific field, however, there is growing overlap in functions and activities of physicians, nurses and other NPCs [37]. Regardless of their level of education or experience, a study of nursing in the U.K. found that the different nursing groups regularly engage in the same range of direct and indirect nursing care [38]. In fact, the blurring borderlines between professional territories imply convergence of the "medical paradigm" and "nursing paradigm" and illustrate lack of agreement over the proper skill mix.

The climate of uncertainty contrasts with ambitions of RN leadership to expand their role in primary care. Some U.S. nurse leaders advocated a substantial expansion of doctoral programs to educate future educators and researchers [39]. Upgrading education levels does not necessary mean expansion of professional activity or an improved organization of work, however.

Physicians and nurses have distinct modes of bargaining over their fees and incomes. Once licensed by a state medical board, American physicians can practice in any setting in that state. They have to bargain with their employer (when employed) over incomes and with insurers over their fees when independent. By 2012, about one third of U.S. physicians were employed by clinics, independent practices or teaching hospitals [40]. In contrast, in Canada and some European countries, there are nation-wide or regional collective wage negotiations. In those countries, medical associations are involved in bargaining with government agencies or health insurers over physician payment. In the U.S., the $\mathrm{CMS}$ and other government agencies set the fee schedules for Medicare, Medicaid and other public insurance. 
Table 4: Nurse practitioners in the United States, by specialty, 1989-2009.

\begin{tabular}{|l|l|l|l|l|l|}
\hline $\begin{array}{l}\text { Year } \\
\text { Specialty }\end{array}$ & $\mathbf{1 9 8 9}$ (numbers) & $\mathbf{1 9 9 9}$ (numbers) & $\mathbf{2 0 0 4}$ (numbers) & $\mathbf{2 0 0 9}$ (numbers) & $\mathbf{2 0 1 6}$ (numbers) \\
\hline Adult & 3,600 & 13,804 & 18,721 & 22,375 & 37,296 \\
\hline Family & 6,000 & 22,508 & 39,964 & 61,500 & 122,322 \\
\hline Gerontology & 720 & 3,876 & 3,977 & 3,750 & 5,995 \\
\hline Pediatrics & 4,080 & 9,996 & 10,573 & 11,750 & 14,208 \\
\hline Women's health & 4,320 & 11,696 & 10,961 & 11,375 & 12,876 \\
\hline Other & 5,280 & 6,120 & 12,804 & 14,250 & 31,301 \\
\hline Total & 24,000 & 68,000 & 97,000 & 125,000 & 222,000 \\
\hline
\end{tabular}

Source: [72].

Traditionally, private insurers typically use those schedules as a template for their own fees. Those one-sided decisions about fees and incomes caused growing dissatisfaction of American physicians [41]. Physicians basically have to accept the rates set by government agencies and private insurance (or only treat patients who will pay out of pocket). The majority of nurses, both in North America and in Europe, work as employees in hospitals and other health care facilities-NPs are more often self-employed (see below). The large number of RNs means that any salary hike translates into a substantial increase in hospital costs-and thus request for higher incomes will face strong resistance. Nurse leaders thus face the hard question whether to bargain as one homogenous group, or to accept greater differentiation in careers and salary levels.

\section{Nurse practitioners}

Advanced Practice Nurses (APNs), are a relatively new profession in America's health care. APNs practice under a variety of titles. For example, nurse practitioner, advance practice nurse, advance nurse practitioner, clinical nurse specialist, professional nurse, expert nurse or nurse consultant [42].

Nurse Practitioners (NP) are one of those. Originally conceived as 'physician extenders,' NPs gained a high degree of professional autonomy, particularly in remote rural areas or inner city clinics with shortage of physicians. In the early 1990s, they had limited autonomy in treatment, prescription and referral [43]. One decade later, despite continued opposition of the AMA and state medical associations, NPs had obtained those privileges as well as independent billing privileges-though with great variation across states [44].

NPs originally had to work in collaboration with physicians or under physician supervision, but their autonomy expanded [45]. NPs in pediatric clinics, for example, provide all routine infant care. Another recent expansion of their domain is in employer-sponsored or department-store clinics. By 2012 there were over 1,000 walk-in clinics, most staffed and managed by NPs [46]. A small but rapidly growing number of NPs work as independent practitioners in outpatient care. According to the Bureau of Labor Statistics, "Nurse practitioners diagnose and treat acute, episodic or chronic illness independently or as part of a health team may focus on health promotion and dis- ease prevention. May order, perform or interpret diagnostic tests and may prescribe medication, Must be RNs who have specialized graduate education" [47]. In fact, there is not much that nurse practitioners cannot take over from (generalist) physicians.

The independent position of the NPs in the U.S. resembles the traditional community nurses in Germany and The Netherlands in the mid- $20^{\text {th }}$ century. Those community nurses visited patients and families at home to provide and organize basic care after childbirth or care in case of severe illness of the housewife, and coordinated care with other health care providers.

The number of registered NPs in the U.S. increased nine fold between 1989 and 2016 (Table 4). By 2016, almost seven percent of all American nurses worked as NP. About four-fifths of the NPs (or about 100,000 NPs-almost as many as FPs!) worked in ambulatory care settings, over half in private physicians' offices and one-fifth in hospitals. Based on current education capacity, the BLS expect further growth of about 30,000 NPs between 2012 and 2012 and an even higher growth of PAs of 33,000 [47].

Most NPs are registered nurses with a master's degree or post-master level training. Educational requirements vary widely. A growing number of U.S. schools do not require RN qualification to become a NP [48]. Some nursing leaders advocated a further upgrade of NP education to the doctorate level [49]. The major NP association embraced this recommendation, but doctoral programs have shown only modest growth [39].

Several studies show that clinics staffed by advanced practice nurses or NPs have similar outcomes as physician-led clinics, confirming the effectiveness of NPs providing medical care $[35,50]$. Those findings prompted nurse leaders to claim the same payment as physicians ('equivalent pay for equivalent work'). The notion of independent medical care by NPs (and PAs) caught the imagination of policy-makers, and the Patient Protection and Affordable Care Act of 2010 (PPACA) announced increased funding for clinics run by NPs. There is, however, lack of cost-effectiveness evidence of substituting nurses for physicians [8,5153]. Educating NPs may be (much) shorter and cheaper than physicians, but without taking into account their relative incomes and the numbers of patients they see each day (and additional costs of referrals, prescriptions and testing), is it hard to assess the cost-benefit ratio of such 
substitution $[37,42,54]$. When NPs takes over activity from physicians, the latter may then expand other, more expensive treatments that will, on balance, increase and not decrease costs [37].

While there is no general agreement on their role, American NPs greatly expanded their scope of practice and autonomy and substantially increased their income level in the last four decades. Some experts argued that they should mostly focus on primary care in ambulatory settings. By 2010, however, NPs had already developed several clinical specialties in hospitals and ambulatory care.

Still, NP leaders in the U.S. expressed loftier ambitions for the future, including higher incomes and fully independent referral and billing capacity. They consider NPs as core professionals in primary care that can, and should, take a more prominent position in coordinating care and leading teams of experts [33]. Ultimately, NPs face the same financial dilemma as other specialized nurses: the more successful they become in gaining professional independence and higher incomes, the less attractive they may become as substitute for physicians. They also have more interest to develop their own fees rather than remain part of the same bargaining group as other nurses.

One major factor explaining the variation in numbers of NPs is geography: large countries with vast sparsely populated rural areas like the U.S., Canada or Australia (as well as urban areas where physicians were less keen to practice) were the first to accept NPs as independent practitioners. Canada-with over 40 years of experience with independent advance practice nurses in remote areas-experimented with NP-led clinics and NPs working in general practice [55]. Some smaller countries including Ireland and Finland-two countries with traditionally high numbers of RNs-also listed relatively high in experimenting with NPs [42]. Other OECD nations, however, ranked much lower.

Barriers to advance practice nursing are professional interests (opposition from medical associations and other health professionals), strategic skills of professional leaders, existing financing arrangements, education and legislation of the scope of practice [42]. Another major barrier is culture. Some countries were slow to start NP training as medical associations opposed the creation of a new profession fearing it would take over some of their work. German and Dutch physicians initially opposed the training of independent NPs. Dutch GPs were reluctant to contract NPs as independent practitioners, for example, but encouraged by government subsidy, they did hire practice nurses ('praktijkverpleegkundigen') as assistants for specific tasks-but not as independent practitioners at equal footing to the physicians $[56,57]$. The wide variety of educational requirement and lack of mutual recognition of NP diplomas across borders poses another barrier for nurses interested to migrate to another workplace.

\section{Physician assistants}

Physician assistants (PAs) are a typical American phenomenon. In few if any other countries independent PAs practice as widely as in the U.S. Pas have a unique historical background [58]. 17th century German Feldshers and $19^{\text {th }}$ century French Officers de Santé worked as medical assistants to alleviate shortages of physicians in the military. In the 1940s, American physicians favored former medics who, after brief training, served as personal assistants in both hospitals and general practice. At the same time, growing concerns over (expected) shortages of health care workers in the late 1950s and 1960s, especially in rural areas, led to calls for the creation of mid-level practitioners. The servicemen returning from the Korean War with basic medical training as corpsmen represented a large untapped source of experienced health care manpower [59]. At first, the education of those assistants (renamed physician assistants, PAs) consisted of two-year vocational training organized by medical schools. It soon opened its door to non-military men as well as women. Over time, PA education gradually extended to the fouryear baccalaureate level and by the early $21^{\text {st }}$ century, the vast majority of graduating PAs (nowadays more women than men) have a master's degree. By the early 1990s, there were 55 programs that graduated 1,600 PAs per year [60]. That number had gone up to 130 in 2006 [61]. The Bureau of Labour Statistics: "Physician assistants practice medicine under the direction of physicians, including examination of patients, diagnosis of illness and injury, and provide treatment" [62].

The range of PA activities and responsibilities depend on state law and on organizational setting. Some organizations, for example the Veteran's Health Administration and California's Kaiser Permanente, embraced PAs (and NPs) as independent professionals. Some physicians are more inclined to delegate work than others to their PAs (or NPs) $[63,64]$. And also, (perceived) shortages of physicians push up the demand for PAs [58]. About two thirds of American PAs work in hospitals, one third in ambulatory settings. PA numbers increased more than fivefold between 1990 and 2016, and there is growing differentiation with the rise of new specialties (Table 5). The rapid growth of PAs working in inpatient settings caused a drop in the share (not in absolute numbers) of PAs working in primary care from 51 to 33 percent [65]. The (relative) decline was greatest for internal medicine, followed by family medicine and pediatrics. Emergency care, surgical care and other medical specialties were the expanding employments places for PAs [49]. The total numbers of PAs continued to grow in all domains and, as noted above, the BLS does not expect leveling off any time soon.

The role of American PAs in primary care is (very) similar to that of NPs [66]. In fact, it is hard to tell the difference between the two groups. PAs, too, have taken over more and more activities from physicians. In many cases, PAs provide a wide range of medical care virtually 
Table 5: Physician assistants in the US by specialty, 1991-2009.

\begin{tabular}{|c|c|c|c|c|c|c|}
\hline $\begin{array}{l}\text { Year } \\
\text { Specialty }\end{array}$ & $\begin{array}{l}1991 \\
\text { (numbers) }\end{array}$ & $\begin{array}{l}1995 \\
\text { (numbers) }\end{array}$ & $\begin{array}{l}2000 \\
\text { (numbers) }\end{array}$ & $\begin{array}{l}2005 \\
\text { (numbers) }\end{array}$ & $\begin{array}{l}2009 \\
\text { (numbers) }\end{array}$ & $\begin{array}{l}2016 \\
\text { (percentages) }\end{array}$ \\
\hline Family medicine & 6,507 & 10,118 & 13,203 & 16,637 & 17,976 & (24.4) \\
\hline Internal medicine & 2,012 & 2,090 & 3,179 & 4,479 & 4,645 & (10.8) \\
\hline Pediatrics & 564 & 674 & 931 & 1,490 & 1,558 & - \\
\hline Other & 11,365 & 14,014 & 22,106 & 36,059 & 48,254 & - \\
\hline Surgical care & - & - & - & - & - & (26.3) \\
\hline Emergency care & - & - & - & - & - & (10.5) \\
\hline Total active & 20,448 & 26,895 & 39,420 & 39,420 & 72,433 & 108,500 \\
\hline
\end{tabular}

Source: AAPA database.

independently in hospitals and outpatient settings, even while formally working under physician supervision. In most U.S. states, PA licenses are more restrictive than those of NPs, but in practice, the degree of professional autonomy of the two groups is quite similar. In ambulatory practice, PAs and NPs provide much the same care as family physicians and general internists. In hospitals, PAs do almost everything that medical residents do. One study estimated that average PA earning in the U.S. $(\$ 94,870)$ even surpassed that of NPs $(\$ 90.580)$ by 2012 , another reported averages incomes of $\$ 98,377$ and $\$ 100,041$ respectively in $2016[18,67]$. As noted above, studies looking into substitution of physicians by PAs found that indeed PAs can do perhaps $80 \%$ of what physicians can do [68]. But as with NPs, it is harder to establish the cost-effectiveness of such substitution-especially when incomes are rising fast.

The PA associations commissioned a task force to explore the creation of a PA clinical doctorate degree in 2009. Interestingly, in contrast to the NP leaders, the task force opposed such a degree [69]. Instead it recommended to a uniform master's degree for all programs (Master of Physician Assistant Practice, MPAP). But as another illustration of the medical orientation of the PAs, the report also suggested a bridge program for PAs with ambitions to become physicians (already about four percent of PAs return to school to get a medical degree).

The idea of PAs spread internationally, as noted above, but slowly and unevenly [70]. PAs are not common in Europe. First of all, European countries did not engage in armed conflicts as much as the U.S. since the Second World War, and hence did not have a large and well-trained group of medics looking for alternative employment. European countries are (much) smaller than the U.S. or Canada, with relative high numbers of nurses and physicians (perhaps explained by the longer history of public funding for healthcare, and stronger public control over education capacities). But also, medical associations seemed to have been more successful in Europe than in the U.S. in defending their professional territories and autonomy. In the mid-2000s, eight industrialized nations had created PA education. The goal was similar: to improve the access to primary care by relieving the time pressure of physicians. But the numbers remained modest.
By the end of the $20^{\text {th }}$ century, policy-makers in Europe widely discussed NPs and PAs as attractive and cost-effective alternatives for physicians, but the actual growth of the two groups of NPCs lagged far behind. In several European countries, well-organized medical associations objected to working with independent NPs and PAs who would take over activities they deemed as unique for the medical profession.

\section{Future Outlook}

This contribution described the changing positions of general internists, family practitioners, nurse practitioners and physician assistants. General internists and family practitioners, for much of the $20^{\text {th }}$ century, were the leading professionals in America's primary care. Their positions had become very similar by the end of the century. They faced similar challenges, some common to the medical profession in general (decline in status, internal fragmentation, budgetary constraints and pressure by 'corporate rationalizers'), some specific to their field (e.g., loss of faith in the cost-saving promise of gate keeping, loss of hospital privileges, waning interest of medical students in primary care), as well as the phenomenal growth of NPCs active in their field.

The contribution also noted a growing gap between the ambitions of GIM and FP leaders to gain (or regain) positions as 'core professionals' in primary care, and the current realities of a narrowing scope of practice and increasing overlap in activities with other groups. The position papers of the GIM and FP associations all but ignore the ambitions of other professional groups. This inward-looking attitude also reflects in the prediction of dire shortages of GIMs and FPs in the next two decades based on straight trend extrapolation. The associations do not seem aware of the rapid growth of other health professionals already firmly established in their territory.

As in North America, policy-makers in Europe expressed high hopes in the substituting physicians by NPCs as a cost-effective solution for (real or perceived) physician shortages. That translated in different forms and speed of substitution across nations. The numbers of qualified and practicing NPs and PAs have been much larger in the U.S. and in Canada than elsewhere. Their scope of activity expanded rapidly, and they gained greater autonomy-especially in prescribing drugs and referrals, with less direct su- 
pervision by physicians then, their counterparts in Europe. With that greater independence, their income levels rose substantially. In Europe, there has been much talk but less action in expanding the numbers and domains of NPs and PAs.

While the professional domains and activities of American PAs and NPs converged, some interesting differences between the two groups remained. NP leaders attached great importance to formalize their independent position, with aspirations for greater professional autonomy (in particular, to gain full formal independence in prescription-writing and billing). They are also seeking increased payment to the same level as physicians for the same activities. In contrast, the PA leadership apparently remained accepting of the hierarchical relation with physicians. Perhaps reflecting their origins in the medical world and education in medical schools, they seem to be respecting the medical model, and were not in search of 'best' model or underlying theories of PA practice as much as nurses. American PAs successfully played the 'credentials inflation' game without much open struggle. PA education, like that of NPs, had moved to the master's level by the early 2000s, and PAs had also developed several clinical specialties. PAs stopped short of pushing for doctorate-level training, however. Those non-confrontational strategies worked well. PA incomes rose faster than those of NPs in the last decade, and graduating PAs easily found employment both in inpatient and ambulatory care. Their disposition and attitude-accepting their hierarchical position, working quietly to upgrade education and income levels without confrontational battles made them attractive collaborators for physicians as reliable and independent co-workers who can do almost all that physicians do (but, as yet, do not claim equal payment).

As noted, the bargaining mode over incomes varies across the different groups. As most PAs and NPs are employed, their incomes are part of wider employment negotiations between employers and labor unions. In contrast, most physicians in primary care are self-employed. They face fee schedules offered by government agencies and private insurers. They can increase their incomes by shifting activities to higher paid categories, in particular where 'pay for performance' leads to higher rewards; or they can increase the number of patients in their practice by hiring assistants and other health professionals.

There has been extensive debate about the appropriate skill mix in primary care in the U.S. and elsewhere, but little general agreement over the 'best' skill mix. National and international data show large variations in numbers of physicians, nurses and others health workers per 1,000 populations, both on the aggregate level and within specific practice settings. That variation also illustrates the substantial overlap in activity and fading borderlines between professional domains.
The traditional processes of professionalization of physicians and others working in health care based on education, access to work and membership of professional associations no longer shield members from outside interference and scrutiny. Nor will they protect the professional group from competition from others, as had become obvious in the field of primary care. That means that the health care professionals in this domain will have to search for new forms of collaboration with others in the future.

A realistic assessment of future health workforce care requires the acknowledgement of several groups of licensed professionals in the medical field-with only few activities exclusive to anyone. This starting point also provides a base for alternative scenarios for the future of 'primary care.' Such scenarios could include, for example, a return to exclusive domains of physicians, nurses and others, each with clearly defined functions and activities; or a more liberal market model with unrestricted overlap in professional functions and activities, or a model that defines a limited range of activities unique to certain professions. Such scenarios also help clarify the organizational consequences of professional roles, functions and activities in primary care, more realistically than categorical statements about the desirability or feasibility of one particular model or one particular position framed by one particular group.

\section{References}

1. Okma KGH, Rojas J, Edelman N (2015) Health Care Professionals Under Pressure: The Changing Field of America's Primary Care. Politiques de Santé, Idées, Innovations et Illusions. Mélanges en l'honneur de Jean de Kervasdoué. Economica, Paris.

2. White J, Marmor TR (2009) Primary Care and Health Reform: Concepts, Confusions and Clarifications. In: Marmor TR, Freeman R, Okma KGH, Comparative Studies and The Politics of Modern Medical Care. Yale University Press, New Haven, USA, 180-202.

3. White WD, Marmor TR (1982) New Occupations, Old Demands: The public regulation of paraprofessionals. J Public Policy Analysis and Management Winter 1: 243-256.

4. Gordon RW Professionals and professionalism: an overview (unpublished paper).

5. Adams TL (2004) Inter-professional conflict and professionalization: dentistry and dental hygiene in Ontario. Soc Sci Med 58: 2243-2252.

6. (2006) Help Wanted: More US Doctors. Projections Indicate America Will Face Shortage of M.D.s by 2020. AAMC, Washington DC.

7. Aiken $L$ (2007) Nursing Shortages: Is there a crisis? If so, what are the implications? 14th Princeton Conference: Health Work Force Issues for the 21st Century, Princeton.

8. Sibbald B, Shen J, McBride A (2004) Changing the skill-mix of the health care workforce. J Health Serv Res Policy 9: 28-38.

9. Duckett SJ (2005) Health workforce design for the 21st century. Aust Health Rev 29: 201-210. 
10. (2015) The Use of Terms Such as Mid-Level Providers and Physician Extenders, AANP.

11. (2008) Health care career income ranges. AMA.

12. Cooper RA, Laud P, Dietrich CL (1998) Current and projected workforce of nonphysician clinicians. JAMA 280: 788-794.

13. Stevens R (1989) In Sickness and in Wealth: American Hospitals in the Twentieth Century. New York: Basic Books.

14. Martin JC, Avant RF, Bowman MA, Bucholtz JR, Dickinson JR, et al. (2004) The Future of Family Medicine: a collaborate project of the family medicine community. Ann Fam Med 2: S3-S32.

15. Gross J (2010) The Hospitalist: A Fast Growing Specialty Helps Patients and Cuts Costs. The New York Times.

16. Moore G, Showstack J (2003) Primary care medicine in crisis: toward reconstruction and renewal. Ann Intern Med 138: 244-247.

17. Hamblin J (2015) What Doctors Make. The Atlantic.

18. Salary.com (nurses, NPs, PAs, FPs).

19. GIM (2003) The future of general internal medicine. Report of the SIM Task Force on the Future of Internal Medicine. Society of Internal Medicine.

20. GIM (2007) Redesigning the practice model for general internal medicine. A proposal for coordinated care: a policy monograph of the Society of General Internal Medicine.

21. (2009) Nurse Practitioners in Primary Care. Policy Monograph. ACP, Philadelphia.

22. Bauer W, Schumm-Draeger PM, Koebberling J, Gjoerup T, Garcia Alegria JJ, et al. (2005) Political issues in internal medicine in Europe. Acta Clin Belg 60: 157-160.

23. Buchan J, O'May F, Ball J (2007) New role, new country: introducing US physician assistants to Scotland. Hum Resour Health 5: 13.

24. (2012) Health At A Glance. Nurses. OECD, Paris.

25. Sheer B, Wong FK (2008) The development of advanced nursing practice globally. J Nurs Scholarsh 40: 204-211.

26. Kleinpell R, Scanlon A, Hibbert D, DeKeyser Ganz F, East $L$, et al. (2014) Addressing Issues Impacting Advanced Nursing Practice Worldwide. Online J Issues Nurs 19: 5.

27. Kaye HS, Chapman S, Newcomer RJ, Harrington C (2006) The personal assistance workforce: trends in supply and demand. Health Aff (Millwood) 25: 1113-1120.

28. Thornley C (2000) A question of competence? Re-evaluating the roles of the nursing auxiliary and health care assistant in the NHS. J Clin Nurs 9: 451-458.

29. Williams A, Sibbald B (1999) Changing roles and identities in primary health care: exploring a culture of uncertainty. $J$ Adv Nurs 29: 737-745.

30. Jacox A (1997) Determinants of who does what in healthcare. Online $\mathrm{J}$ of Issues in Nursing.

31. Carmel S (2006) Boundaries obscured and boundaries reinforced: incorporation as a strategy of occupational enhancement for intensive care. Sociol Health IIIn 28: 154177.

32. Coburn D, Rappolt S, Bourgeault I, Angus J (1999) Professional Autonomy and the Problematic Nature of Self-regulation: Medicine, Nursing and the State. Garamond Press, Ontario.
33. English T (1997) Personal paper: medicine in the 1990s needs a team approach. BMJ 314: 661-663.

34. (2007) White Paper on the Education and Role of the Clinical Nurse Leader. AACN, Washington DC.

35. Mundinger MO (2002) Twenty-first-century primary care: new partnerships between nurses and doctors. Acad Med 77: 776-780.

36. Murphy EC, Ruch S, Pepicello J, Murphy M (1997) Managing an increasingly complex system. Nurs Manage 28: 33-38.

37. Lankshear A, Sheldon T, Maynard A, Smith K (2005) Nursing Challenges: are changes in the nursing role and skill mix improving patientcare? Health Policy Matters, University of York.

38. Jenkins-Clarke S, Carr-Hill R (2003) Workforce and workload: are nursing resources used effectively? J of Research in Nursing.

39. (2004) Position Statement on the Practice Doctorate in Nursing. AACN, Washington DC.

40. (2015) Occupational Employment Statistics. 29-1071 Physician Assistants. BLS, U.S. Department of Labor, Washington DC.

41. Zuckerman S, McFeeters J, Cunningham P, Nichols L (2004) Changes in medicaid physician fees, 1998-2003: implications for physician participation. Health Aff (Millwood), W4374-384.

42. Lafortune $G$ (2011) Development of advanced nursing roles in European and non-European countries. OECD, Paris.

43. Safriet BJ (1992) Health Care Dollars and Regulatory Sense: The Role of Advanced Practice Nursing. The Yale J on Reg 9: $417-488$

44. Phillips SJ (2007) A comprehensive look the legislative issues affecting advanced nursing practice. Nurse Pract 32: 14-17.

45. Goolsby MJ (2005) 2004 AANP National Nurse Practitioner Sample Survey, part I: an overview. J Am Acad Nurse Pract 17: 337-341.

46. Banjo S (2012) Wal-Mart Lags in Clinic Race. The Wall Street Journal.

47. (2015) Occupational Employment Statistics 29-1171. Nurse Practitioners. BLS, US Department of Labor, Washington D.C.

48. Pulcini J, Wagner M (2002) Nurse Practitioner education in the U.S.: A Growing Success Story, Clinical Excellence for Nurse Practitioners 6: 38-41.

49. Mundinger MO (2007) Evidence, Value and the Role of Doctors of Nursing Practice. 14th Princeton Conference: Health Workforce Issues for the 21st Century, Princeton.

50. Horrocks S, Anderson E, Salisbury C (2002) Systematic review of whether nurse practitioners working in primary care can provide equivalent care to doctors. BMJ 324: 819-823.

51. Richardson G (1999) Identifying, evaluating and implementing cost-effective skill mix. J Nurs Manag 7: 265-270.

52. Martínez-González NA, Djalali S, Tandjung R, Huber-Geismann F, Markun S, et al. (2014) Substitution of physicians by nurses in primary care: a systematic review and meta-analysis. BMV Health Serv Res 14: 214.

53. VanVleet A, Paradise J (2015) Tapping Nurse Practitioners to Meet Rising Demand for Primary Care. Issue Brief. 
54. Sox HC (2000) Independent primary care practice by nurse practitioners. JAMA 283: 106-108.

55. DiCenso A, Bourgeault I, Abelson J, Martin-Miserner R, Kaasalainen S, et al. (2010) Utilization of nurse practitioners to increase patient access to primary healthcare in canada-thinking outside the box. Nurs Leadersh 23: 239-259.

56. Schoen C, Osborn R, Huynh PT, Doty M, Peugh J, et al (2006) On the front lines of care: primary care doctors' office systems, experiences, and views in seven countries. Health Aff (Millwood) 25: 555-571.

57. Pleegkaat (2013) Nunieuws: de Praktijkverpleegkundige/ondersteuner.

58. Cawley JF, Hooker RS, Pederson D (undated paper). Origins of the Physician Assistant Movement in the United States.

59. Cawley JF, Hooker RS (2003) Physician Assistants in American Medicine : the half-century mark. Am J Manag Care 19: e333-e341.

60. Osterweis M, Garfinkel S (1993) The roles of physician assistants and nurse practitioners in primary care: an overview of the issues. In: Clawson DK, Osterweis M, The Roles of Physician Assistants and Nurse Practitioners in Primary Care. Association of Academic Health Centers, Washington DC.

61. Cawley JF (2008) Physician assistants and Title VII support. Acad Med 83: 1049-1056.

62. Occupational Employment Statistics, several years, 19892008. BLS, U.S. Department of Labor, Washington D.C.

63. Kreimer S (2014) Building Better Care Teams with Non-Physician Providers. Medical Economics.

64. Clawson DK, Osterweis M (1993) The Roles of Physician Assistants and Nurse Practitioners in Primary Care. Association of Academic Health Centers, Washington D.C.

65. (2009) Physician Assistant Census Report. AAPA.
66. McCaig LF, Hooker RS, Sekscenski ES, Woodwell DA (1998) Physician assistants and nurse practitioners in hospital outpatient departments, 1993-1994. Public Health Rep 113: 75-82.

67. Advance (2012) The 2012 National Salary Survey of NPs and PAs.

68. Buchan J, Dal Poz MR (2002) Skill mix in the health care workforce: reviewing the evidence. Bull World Health Organ 80: 575-580.

69. (2009) Physician Assistant Clinical Doctorate Summit: Final Report and Summary. AAPA, Alexandria.

70. Hooker RS, Hogan K, Leeker E (2007) The Globalization of the Physician Assistant. The $\mathrm{J}$ of Physician Assistant Education 18: 76-85.

71. Occupational Employment Statistics, different years, 19752012. BLS, U.S. Department of Labor, Washington D.C.

72. (2006) Physician Characteristics and Distributions in the US. (2006 edn), AMA, Washington D.C.

73. (2012) Physician Characteristics and Distribution in the US. (2012 edn), AMA.

74. Goolsby MJ (2009) 2009 AANP membership survey. J Am Acad Nurse Pract 21: 618-622.

75. (2008) Specialty Specific Information. AMA, Washington D.C.

76. Fujisawa R, Lafortune $G$ (2008) The remuneration of general practitioners and specialists in 14 OECD countries: what are the factors influencing variations across countries? OECD (Working Paper), Paris.

77. Merritt Hawkins and Associates (2008) Review of Physician and CRNA Recruiting Incentives.

78. Arvantes J (2013) Family Physician Salaries Rising, Says Survey. AAFP.

79. Worldsalaries.org/professionalnurses.shtml1.4/9/13 